\title{
Lenguas y toponimias en la zona andina de Áncash
}

\author{
Languages and toponyms in the Andean region of Ancash
}

Félix Julca Guerrero ${ }^{1}$ y Laura Nivin VArgas ${ }^{1}$

\section{RESUMEN}

Esta investigación da cuenta de la vigencia de topónimos pertenecientes a diferentes lenguas que antiguamente se hablaron en la zona andina de Áncash. Para entender nuestro pasado histórico, conocer el presente y proyectarnos al futuro, consideramos importante realizar un estudio de las herencias linguoculturales andinas basado en los topónimos o nombres de lugares geográficos. El objetivo principal fue pesquisar y analizar los topónimos desde las perspectivas de la lingüística descriptiva, lingüística histórica y contacto de lenguas. La investigación fue de tipo exploratorio y descriptivo; para ello se utilizó los métodos de análisis lingüístico de la data. Los datos empíricos revelan que en la actualidad aún se registran topónimos correspondientes a las lenguas quechua, culli, aimara y castellana; así como topónimos mixtos que proceden de la combinación léxica o léxico-morfofonológica de dos lenguas diferentes. En tal virtud, a partir del análisis de la toponomástica se concluye que, históricamente, Áncash fue un contexto marcado por la diversidad lingüística y, por ende, por la diversidad sociocultural.

Palabras clave: toponimias; lenguas originarias; quechua; aimara; culli.

\begin{abstract}
This research from the analysis of toponyms shows the presence of indigenous languages in the Andean region of Ancash. Given that, to understand our historical past, meet the present and to project the future, we consider it important to conduct a study of the Andean heritage linguoculturales based on geographical names. The main objective was to collect and analyze place names from the perspectives of descriptive linguistics, historical linguistics and language contact. The research was exploratory and descriptive methods for this linguistic analysis of the data was used. Empirical data show that even today he names corresponding to the Quechua guides, Culli, Aymara and Spanish are recorded; and mixed names coming from the lexical or lexicalmorphonological combination of two different languages. As such, from the analysis of the place names we conclude that, historically, Ancash was a context marked by linguistic diversity and hence, by the sociocultural diversity.
\end{abstract}

Keywords: toponyms; native languages; Quechua; Aimara; Culli.

1 Universidad Nacional «Santiago Antúnez de Mayolo». Huaraz, Perú. 


\section{ICHIKLLACHAW}

Kay musyapakuyqa riqitsimantsin imanawmi kanankamaraq tupunimyakuna kawaykanqanta, unay unay tukuy laaya shimikunachaw kay Anqash suyuntsikchaw rimayanqantam. Tsaynawpa ñawpa kanqanta kaayinapaq, kanan kaqta riqinapaq, kananpiq ñawpaman shamunqanta rikaanapaq. Tsayraykurmi antikunachaw kay unay shimi yachay musyapakuy tupunimiyakunachaw kanqantam riqitsikun, kay shutikunaqa llaqta patsakunapa shutinkunam kayan. Kay musyapakuyqa rurakashqa imanawmi tupunimyakunapa kikin shiminkunachaw willakuynin kanqanta musyatsimantsin, hinaman imanawmi unay shiminkunachaw willakuykuna kanqantawan kanan shiminkunachaw tinkuynin kanqantawanmi willakun, tsay llapanta rurakashqa alliq riqinantsikraykurmi. Kay musyapakuyqa isplurasyunwan diskriptibu ashipakuy laayaman kashqa, tsaypaqmi analisis linguistiku mitudu shutiyuq nishqanwan rurakashqa. Kay impiriku datukunam riqimantsik imanawmi qichwachaw, kullichaw, aymarachaw hina kastillanu shimikunachaw kanankama kawaykanqantaraq; hinaman imanawmi takukashqa tupunimiyakuna ishkay tahukashqa shimikunapiq shayaamunqantam riqitsimantsik. Kay tupunimiyakuna analisashqapitam uchuklla shimillachaw nintsik, unaypitam Anqash suyupaqa atska laaya shiminkuna kashqa, runankunapa tukuy laaya yachayninkuna kashqanraykurmi.

Pushaq shimikuna: tupunimiyakuna; qichwa; aymara; kulli; shimikunapa yurikuyninkuna.

\section{INTRODUCCIÓN}

El presente artículo analiza los topónimos de la zona andina de Áncash, cuyo registro evidencia la presencia histórica de las lenguas quechua, culli y aimara. Si bien desde la antigüedad ha existido un creciente interés por el estudio de los nombres geográficos, los cuales son utilizados como posibles evidencias de las hipótesis acerca de la historia de las lenguas y grupos humanos de determinadas áreas geográficas, en el caso de la zona andina de Áncash, los estudios aún son insuficientes. En concordancia con Solís (1997), Chávez (2003) y Cerrón-Palomino (2008), con el término 〈toponimia〉 nos referimos a los nombres de lugares, sean estos habitados o no. Los topónimos expresan el criterio señalizador practicado por el hombre sobre los espacios geográficos que alcanza a caracterizarlos o simplemente nombrarlos. En tal virtud, son topónimos los nombres de pueblos, ríos, lagos, lagunas, chacras, cerros, nevados, parajes, calles, caminos, etcétera. De esta manera, las lenguas habladas en la zona andina de Áncash pueden ser claramente reconocidas a través de los nombres de lugares (topónimos), elementos léxicos y terminaciones morfológicas que caracterizan a las lenguas aimara, culli y quechua.

En este marco, con esta investigación sobre la base de los topónimos se buscó dar cuenta de la presencia histórica de diferentes lenguas originarias o indígenas en la zona andina de Áncash. El propósito principal fue pesquisar y analizar los nombres actuales de lugares en las zonas del Callejón de Huaylas, los Conchucos y las Vertientes. Para el acopio de datos se utilizaron las técnicas e instrumentos propios de las investigaciones exploratorias y descriptivas. Además, dado al carácter exploratorio y descriptivo de la 
investigación sobre la presencia de lenguas originarias y el contacto entre ellas en el contexto andino de Áncash, las preguntas de investigación -antes que las hipótesisfueron las que guiaron el proceso de la investigación.

Los resultados de esta investigación han permitido conocer que en la zona andina de Áncash, históricamente, no solo se habló el quechua, sino también el culli (lengua extinta alrededor de 1940, cf. Rivet, 1949) y el aimara hablado antes de la expansión del quechua, hoy concentrado en la zona sur del altiplano peruano y boliviano, principalmente. Los topónimos en las lenguas originarias, en este caso aimara, culli y quechua han sufrido cambios o alteraciones en su imagen gráfica, sea porque la lengua ha sufrido variaciones morfofonológicas o porque su ortografía tiende a castellanizarse asimilándose a una configuración más o menos similar a la del castellano. Es decir, esto puede obedecer a la evolución interna de la misma lengua o a un acomodamiento al castellano para «facilitar»su ortografía. Por esta razón, muchos de los topónimos en lenguas originarias han sido refonemizados y refonologizados con base castellana y, también escritos con ortografía castellana con base en el alfabeto también castellano. Por consiguiente, si bien las lenguas culli y aimara ya no se hablan en Áncash y el quechua se encuentra en un franco proceso de desplazamiento y sustitución lingüística en muchos ámbitos sociogeográficos de la zona andina de Áncash; sin embargo, la presencia de dichas lenguas se nota vigente en los topónimos.

\section{MATERIALES Y MÉTODOS}

El universo de estudio comprendió la totalidad de las provincias andinas de la región Áncash (17), correspondientes a las Vertientes, el Callejón de Huaylas y los Conchucos. Para el acopio de datos se ha utilizado varias técnicas e instrumentos como la entrevista aplicada a los lugareños de los pueblos visitados, así como el fichaje de registro de topónimos. Asimismo, se hizo una revisión de los documentos más antiguos como escritos y testimonios en el archivo de las municipalidades y la oficina de Archivos de Huaraz; mapas geográficos y la lista de 43 palabras de Martínez Compañón (1978 y 1779). Se complementó con la vista a algunos lugares donde se recogieron datos desde la versión de los propios pobladores.

El trabajo de investigación se enmarcó en los casos de los estudios exploratorios y descriptivos. Fue exploratorio porque no se cuenta con antecedentes suficientes sobre el tema, razón por la cual antes que las hipótesis fueron las preguntas que guiaron la investigación. Los trabajos más rescatables para este propósito fueron los de Adelaar (1989) «En pos de la lengua culle», Solís (1997) «La gente pasa, los nombres quedan... introducción en la toponimia» y Chávez (2003) «La toponimia en la zona andina de Áncash». Fue descriptivo, porque su propósito ha sido pesquisar y describir de una manera pormenorizada los nombres topónimos de pueblos, cerros, lagunas, caminos, minas, etcétera, según su morfología geográfica, a la luz de los aportes de la lingüística descriptiva, lingüística de contacto de lenguas y la lingüística histórica. Ambos procesos tuvieron el componente analítico; esto nos permitió analizar, identificar y filiar los topónimos a las correspondientes lenguas. 


\section{RESULTADOS}

\section{Lenguas y toponimias en Áncash}

Una breve revisión de la literatura especializada revela que, en el territorio actual de la región Áncash, desde épocas muy remotas vivieron diferentes grupos humanos con características socioculturales propias y peculiares que los distinguían a los unos de los otros (Torero, 2002). Por ejemplo, entre los siglos VII y XI d.C., la expansión del aimara central habría alcanzado hasta el actual territorio de la región Áncash (cf. Cerrón-Palomino, 2000). Heggarty y Beresford-Jones (2010, 2012) consideran a Chavín como la cultura difusora no solo del «Pre-Proto-Quechua», sino principalmente del aimara. Esto implica que en Áncash, se habló aimara antes de que fuera desplazado por el quechua. También en la zona norte de Áncash, sierra de La libertad y Cajamarca se habló la lengua culli o culle (Adelaar, 1989). Estos datos dan cuenta que, Áncash, históricamente, se ha caracterizado por la diversidad cultural y lingüística. Precisamente, a la llegada de los españoles, aún existían cuatro grupos etnolingüísticos bien diferenciados: el quechua y el culli ${ }^{2}$ en la zona andina, el quingnam y el mochica en la zona $\operatorname{costeña}^{3}$ (Solís, 2003; Julca, 2004, 2009a).

La pesquisa de topónimos da cuenta, realmente, que en la región Áncash se hablaron varias lenguas en el pasado no muy lejano. En la actualidad, el mayor porcentaje de los nombres de lugares en la zona andina corresponden a lenguas originarias antes que al idioma castellano. No obstante, muchos nombres toponomásticos en lenguas originarias, en este caso, aimara, culli y quechua han sufrido cambios o alteraciones en su imagen gráfica, sea porque la lengua ha sufrido variaciones morfofonológicas, variaciones por influencia externa como efecto del contacto de lenguas ${ }^{4}$ o porque su ortografía tiende a castellanizarse asimilándose a una configuración más o menos similar a la del castellano. Es decir, esto puede obedecer a la evolución interna de la misma lengua, cambios motivados por contacto de lenguas o a un acomodamiento al castellano para «facilitar»su ortografía. Por ejemplo, en el topónimo Ranrairca, el segundo elemento léxico irca es el resultado del cambio fonético $/ \mathrm{h} />[\varnothing]^{5}$, es decir, el sonido fricativo /h/ se elide y no se pronuncia $[\varnothing]$ en inicio de palabra que es común en el quechua hablado en la zona norte del Callejón de Huaylas: irka < birka, pero la escritura con 〈C〉 irca obedece simplemente al acomodamiento ortográfico del castellano para facilitar la ortografía en los castellanohablantes y bilingües (véase Julca, 2009a). Los cambios

\footnotetext{
2 En la parte norte andina de Áncash, además del quechua, la lengua culli todavía fue hablada hasta mediados del siglo pasado (Adelaar, 1989; Andrade y Pérez, 2009; Rivet, 1949; Solís, 2003).

3 Las evidencias de la presencia de las lenguas mochica, muchik o yunga, así como de quingnam o lengua del pescador las encontramos en los documentos de la colonia (véase por ejemplo, la lista de 43 palabras del obispo de Trujillo, Martínez de Compañón, así como en la onomástica (topónimos y antropónimos). Así, sabemos que las palabras Ferreñafe, Quesquen, Niquín corresponden al mochica y las palabras Pacatnamu 'padre común' y Taycanamo 'fundador de Chimú' pertenecen al quingnam.

4 Es sabido que, en una situación de contacto lingüístico, las lenguas implicadas no pueden permanecer «químicamente puras» por mucho tiempo, sino que experimentan interinfluencias y cambios estructurales en diferentes niveles de la lengua, situación que se evidencia en los topónimos de la región (véase Julca, 2004).

5 La equivalencia de los símbolos es la siguiente: el asterisco $*$ indica que la palabra corresponde al Proto-Quechua o es la palabra originaria, las barras // encierran la representación fonémica o fonológica, los corchetes [] representan la pronunciación, el símbolo > significa lo que precede da lugar a lo que sigue, el símbolo < significa lo que precede es el resultado de lo que sigue, el guión - señala el linde morfémico en la palabra, las comillas anguladas () encierran la escritura grafémica, las comillas simples "' encierran la traducción castellana.
} 
ortográficos más frecuentes en los topónimos quechuas de la zona corresponden a: q $>\mathrm{c}($ aqu $>$ Aco), $\mathrm{k}>\mathrm{c}($ markaq $>$ Marcac), $\mathrm{sh}>\mathrm{s}$ (waywash > Huayhuas, hanqash > Jangas), sh $>\mathrm{z}$ (qarash $>$ Caraz), $\mathrm{k}>\mathrm{g}$ (yunkay $>$ Yungay) $\mathrm{h}>\mathrm{j}$ (birka $>$ jirca), $\mathrm{w}>\mathrm{v}$ (wikus $>$ Vicos), $\mathrm{w}>$ hu (waras $>$ Huaraz), $\mathrm{u}>$ o (tuqlla $>$ Toclla), i $>$ e (wankapiqtuy $>$ Huancapeti). Aun cuando ortográficamente se escriben con acomodamiento al castellano, los quechuahablantes, mayormente, siguen pronunciando como naturalmente lo hacen en su lengua.

En la zona andina de Áncash es frecuente encontrar que un mismo lugar tenga dos nombres en lenguas diferentes: Dos de Mayo y Tímac, Trinidad y Pachaca (en La Merced, Aija), Santa Catalina y Shutu (Huaraz) o tengan nombres compuestos en la misma lengua como en los casos de Utcuyacu (utku 'algodón' y yaku 'agua', lugar de agua muy cristalina), Yanayacu (yana 'negro' y yaku 'agua'), Cancharumi (kancha 'corral' y rumi 'piedra'), (en Recuay) o compuesto por palabras de lenguas diferentes como en Marcajirca (marka 'pueblo' = aimara y birka 'cerro' = quechua), Hornojircan (horno = castellano y birkan 'ladera' = quechua), (en Huari); Ticapampa (tika <*t'ika 'flor' = aimara y pampa 'llanura' = quechua), (en Recuay); Quinircocha (qirnir 'hermano' = culli y qucha 'laguna' = quechua), (en Cabana). En otros casos, los nombres originarios han sido sustituidos por nombres en otras lenguas, tal es el caso de Awkis Mayu o Hatun Mayu y Ranra que han sido sustituidos por las nominaciones castellanas Río Santa y Pedregal (un barrio en Huaraz), respectivamente.

Los topónimos nombrados en el párrafo anterior develan la presencia simultánea o consecutiva en un mismo lugar de Áncash de gentes de diversa procedencia lingüística, étnica y cultural. Los nombres de lugares proceden no solamente del quechua, la lengua originaria aún más difundida en el contexto regional, sino también de otras lenguas como aimara, culli y castellana. A continuación presentamos una lista seleccionada de topónimos que ilustra el origen lingüístico variado de los nombres de lugares geográficos en la zona andina de Áncash.

\section{Toponimias en la zona andina de Áncash}

Del total de 865 topónimos registrados, en esta sección se presenta solo una muestra de los nombres de lugares más representativos para el análisis lingüístico. Se los presenta agrupados en lenguas independientes, luego dada la mayor cantidad de topónimos quechuas se analiza dichos nombres, así como los topónimos híbridos resultantes de la combinación de entradas léxicas o elementos morfológicos pertenecientes a lenguas diferentes.

\subsection{Topónimos aimaras}

Los topónimos aimaras se encuentran en diferentes partes de la región Áncash.

$\begin{array}{ll}\text { Marca } & <\text { marka 'pueblo' (en Recuay). } \\ \text { Marcac } & <\text { marka-q 'fundador de pueblo' (en Huaraz). } \\ \text { Marcará } & <\text { marka 'pueblo', -ra 'continuidad' (en Carhuaz). } \\ \text { Áncash } & <\text { anqas 'azul' (*anqas vocablo aru o quechumara). }\end{array}$




\subsection{Topónimos culli}

Los topónimos culli se encuentran básicamente en la zona norte de los Conchucos, principalmente en la provincia de Pallasca.

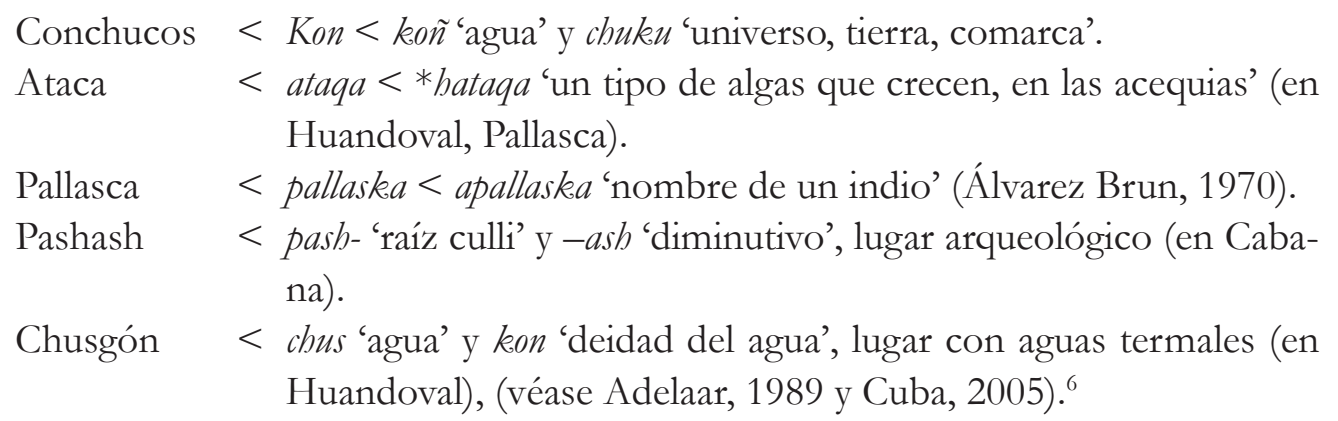

\subsection{Topónimos castellanos}

Los topónimos castellanos se encuentran en diferentes partes de la zona andina de Áncash. En muchos casos los nombres castellanos fueron impuestos sobre los nombres en otras lenguas. Asimismo, en los últimos años, los pobladores de las zonas urbanas y urbano-marginales han ido cambiando los nombres quechuas por nombres castellanos. Tal es el caso de las famosas villas: Urbanización Villa El Sol, Urbanización Villa San Pedro, etcétera., bajo la creencia de estar a tono con la modernidad:

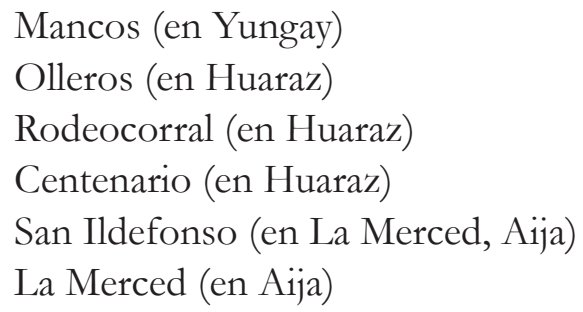

\subsection{Topónimos quechuas}

La mayor parte de los nombres de lugares en la zona andina de Áncash, principalmente en el Callejón de Huaylas y Las Vertientes, proceden del quechua, lengua originaria más difundida en el ámbito regional, así como en toda la zona andina de los países andinos. En tal virtud, se puede identificar diferentes mecanismos de acuñación toponomástica que han realizado los hablantes en épocas concretas. Los topónimos de este corpus están agrupados en tres bloques: (1) palabras de una sola raíz, (2) palabras derivadas y (3) palabras compuestas.

(1) Palabras conformadas por una única raíz. Estas palabras contienen solamente morfemas lexicales del quechua.

\footnotetext{
${ }^{6}$ Asencios (2013) considera que la palabra quita < kita 'laguna, lago' (reservorio de agua en las chacras) es un término culli; no obstante, Francisco Carranza (2003) en su Diccionario Quechua Ancashino-Castellano, recoge la palabra quita < qita como un término quechua con el significado de 'lodo, barro, pantano, limo'.
} 


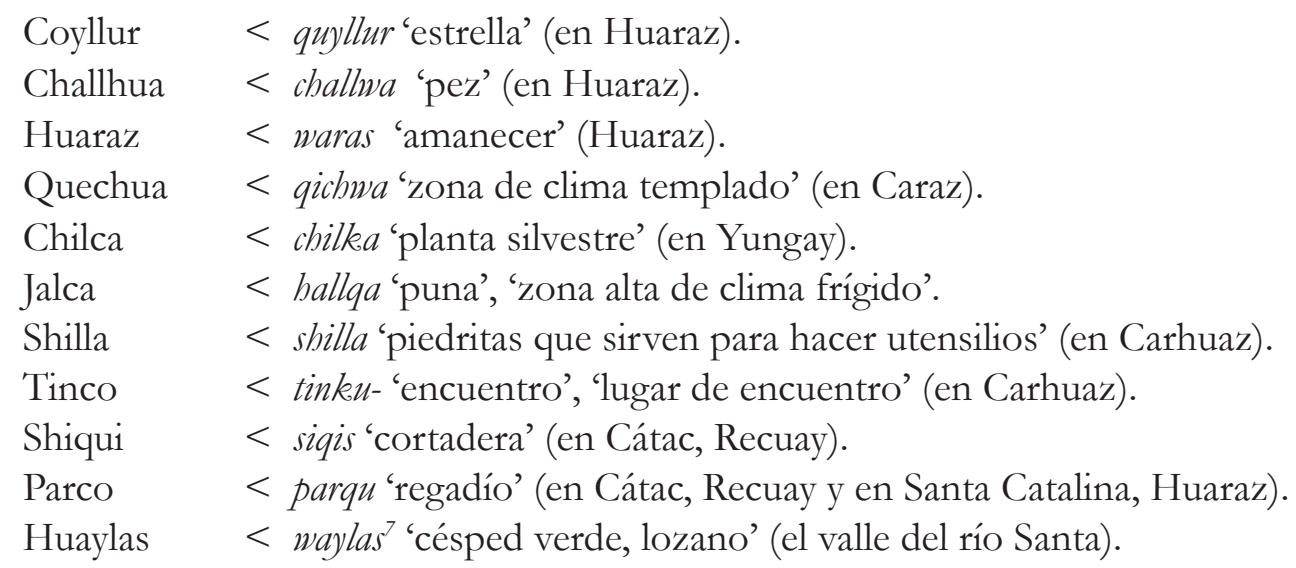

(2) Palabras derivadas. Este grupo de palabras está constituido por aquellas derivadas por sufijación. Los topónimos están conformados por una raíz y un sufijo. Los sufijos derivativos más comunes en los topónimos ancashinos son: $-q,-y,-r a,-r i,-n,-n a,-s h$, -shqa, -yuq (cf. Chávez 2003).

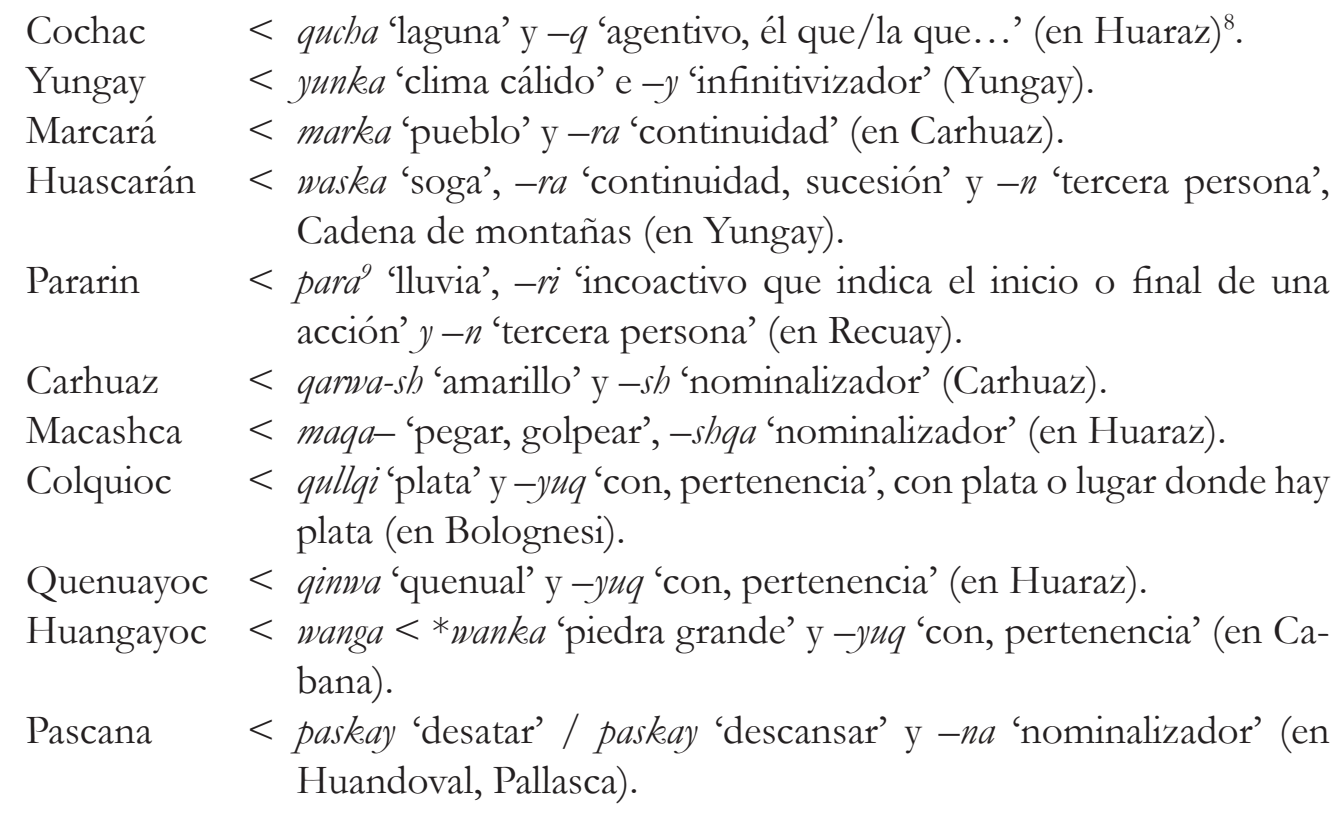

(3) Palabras compuestas. Las palabras compuestas de los topónimos no son otra cosa que frases nominales. Una frase nominal es una forma lingüística que contiene un núcleo nominal y elementos modificadores o complementadores. Los topónimos com-

\footnotetext{
La palabra Waylas también es usada como antropónimo, apellido de la ñusta Qishpi Sisa Inés Waylas (hija del inca Wayna Qapaq, hermana menor de Atawallpa y Waskar). Pizarro, al tomar como segunda esposa a Inés Waylas, ordenó en honor a ella nombrar como Waylas a todo el valle del Awkis Mayu (Río Santa). Posteriormente, con esta palabra Waylas escrita como «Huaylas» se nombró a la música y danza de competencia entre hombres y mujeres (cf. Alba, 2008; Carranza, 2003).

8 Este mismo proceso se da en el caso de Rímac < rima 'hablar', $-q$ 'agentivo', 'hablador o el que habla' (en Lima). Otro proceso se da en Paramonga < para 'lluvia', $-m u$ 'direccional de allá para acá' y -nga $<*$ *nqa 'subordinador' (en Lima).

9 En el quechua sureño y norteño se usa la palabra para 'lluvia', mientras que en el quechua central se usa la palabra tamya. En el caso de Paramonga y Pararín, la palabra para corresponde al léxico de la variante sureño-norteña del Quechua.
} 
puestos quechuas están formados mayormente por dos raíces fusionadas en una sola $\mathrm{y}$, a veces complementadas con algunos elementos derivativos.

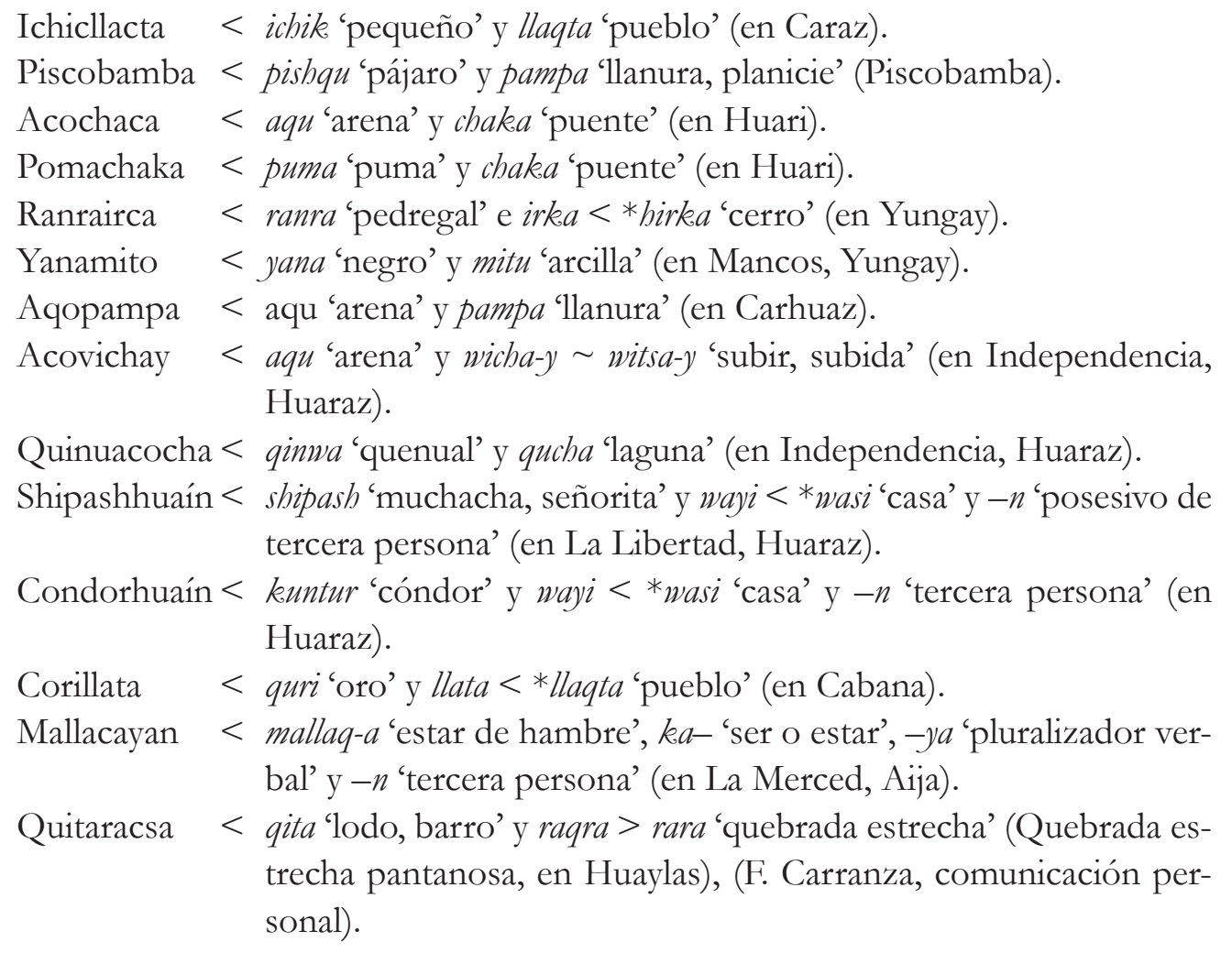

\subsection{Topónimos híbridos}

Hay nombres de lugares que tienen un origen híbrido, mixtificado o mezclado. En dichos topónimos se han combinado palabras base que proceden de lenguas diferentes. Se han registrado topónimos con las combinaciones: quechua-culli, aimara-quechua, castellano-quechua y castellano-culli.

\footnotetext{
Marcajircan $<$ marka 'pueblo' = aimara y jirkan $<*$ birkan 'ladera' = quechua

Julcanpampa $<$ bulka $<$ sulka $<*$ shullka 'hijo menor' = aimara y pampa 'llanura' = quechua

Ticapampa $<$ tika $<*$ t'ika 'flor' = aimara y pampa 'llanura' = quechua

Cocaball $\quad<$ kuka 'coca' = quechua y ball $\sim$ ball (e) 'falda de cerros' = culli

Salaballe $\quad<$ sala $<*^{*}$ sara 'maíz' $=$ quechua y balle 'repliegue o falda de cerros' $=$ culli (Torero 1989)

Dos de Mayo de Tímac $<$ Dos de Mayo $=$ castellano y timac $<*$ kima-q 'tres fundadores' = quechua

Cruzpampa $<$ cruz $=$ castellano y pampa 'llanura' = quechua

Botonjirca $<$ botón = castellano y birka 'cerro' = quechua
} 


$$
\begin{aligned}
& \text { Cedroball }<\text { cedro = castellano y ball } \sim \text { ball }(e) \text { 'falda de cerros' }=\text { culli } \\
& \text { Santiago de Chuco }<\text { Santiago }=\text { castellano y chuku }=\text { culli } \\
& \text { Quitaracsa }<\text { qita }=\text { lodo, barro = quechua y raqra }>\text { rara }=\text { quebrada estrecha. }
\end{aligned}
$$

El corpus de topónimos presentados evidencia el complejo origen de los nombres de lugares en la región Áncash. Ello responde, justamente, a que en este ámbito geográfico históricamente se habló lenguas diferentes y cada una de ellas ha dejado su huella en los topónimos. Por consiguiente, para filiar los nombres toponomásticos no solamente debemos basarnos en las lenguas que actualmente se habla, sino se debe hacer un rastreo de las otras lenguas habladas en el pasado. Asimismo, los topónimos evidencian que Áncash, históricamente, se ha caracterizado por ser un contexto de diversidad cultural y lingüística.

\section{DISCUSIÓN}

A partir de la toponimia se puede colegir la presencia de diferentes lenguas en la zona andina de Áncash, empero dichas lenguas no mantuvieron una relación horizontal sino jerárquicamente organizada con rasgos de diglosia. La condición de superposición y subordinación de lenguas se refleja no solo en el habla real cotidiana, sino también en los topónimos. Así, el análisis de los topónimos de Áncash nos permite hipotetizar cómo las lenguas y las culturas se superponen. En este caso concreto, cómo el culli y el aimara fueron encerrados por el quechua; más tarde, el culli, el aimara y también el quechua, se vieron subordinados y desplazados por el castellano ( $f f$. Cerrón-Palomino, 1988). A pesar de ello, aún el mayor porcentaje de los términos toponomásticos registrados en Áncash corresponden al quechua, dado que es la zona donde se habló esta lengua desde la época de sus orígenes (Torero, 1975, 2002) y es la lengua originaria más grande tanto por su distribución geográfica que abarca casi toda la región ancashina y departamentos vecinos a nivel micro y los seis países andinos a nivel macro, así como por la cantidad de cerca de un millón de personas que la hablan en la región (Julca, 2009a, b).

El estudio de la toponimia es de por sí importante. Pero esta importancia es mucho mayor en lugares como Áncash en cuyo territorio se dieron en otras épocas ocupaciones sucesivas de un mismo hábitat por gente de diferente lengua. Los grupos humanos que son reemplazados por otros en la ocupación de un territorio dejan, como rastros de su paso, palabras de sus respectivas lenguas en forma de topónimos de los distintos lugares ocupados (Adelaar, 1989; Cerrón-Palomino, 2008; Hegagarty y BeresfordJones, 2010). Aquí radica la importancia heurística de la toponimia, pues siendo rastro, nos puede dar información acerca de la historia del asentamiento y poblamiento de un lugar, lo cual es fundamental para la reconstrucción de la historia social andina y, en este caso particular, de la zona andina de Áncash.

Las lenguas en general y la lengua quechua en particular emplean en una forma bastante sistemática el uso de características del ambiente y contexto geográfico como mo- 
tivación para la designación toponímica. Los colores del entorno, las particularidades morfológicas de los lugares, las plantas y minerales, las personas y grupos humanos aparecen a menudo como motivos para la designación (Chávez, 2003; Solís, 1997). Es frecuente que los nominales, cuando son usados en la toponimia, aparezcan con los sufijos, $-n,-s,-y,-r a,-s h,-y u q,-s h q a$, etcétera, que sirven para caracterizar el lugar por la presencia de lo que alude el nominal al que se le sufija tales partículas.

La zona andina de Áncash nos ofrece una abundante información toponomástica. Los topónimos no son sino la muestra del inventario linguocultural organizado históricamente por el hombre (cf. Asencios, 2013; Chávez, 2003; Cuba, 2005). En Áncash, la toponimia es particularmente rica por la diversidad de lenguas que se habló en el pasado cuyas huellas encontramos en los topónimos de origen quechuamara, aimara, culli, quechua, principalmente, acuñados bajo la modalidad de raíces simples, raíces derivadas o palabras compuestas. Dichos topónimos ahora constituyen parte de nuestra identidad como pueblo y cultura andina.

\section{CONCLUSIONES}

El registro y análisis de los topónimos en la zona andina de Áncash evidencia la existencia y coexistencia de las lenguas aimara, quechua y culli en el pasado. Asimismo, la cuantificación de los topónimos hace entrever la superposición del quechua al aimara y el desplazamiento de este último. A su tiempo, el castellano se superpuso no solo al quechua sino también al resto de las lenguas y terminó desplazándolos. No obstante, en el caso de los topónimos dicho desplazamiento no ocurrió, sino solo la incorporación de algunos elementos léxicos castellanos para nombrar los lugares.

Los topónimos en la zona andina de Áncash corresponden a cuatro lenguas: aimara, culli, quechua y castellano. Los topónimos aimaras son escasos con relación a los de las otras lenguas. Los topónimos culli se encuentran, mayormente, en la zona de Pallasca y lugares aledaños. Por su parte, los topónimos quechuas y castellanos se encuentran en todas partes de la región ancashina.

Algunos topónimos mantienen la escritura en la forma original de la lengua, pero la gran mayoría han sufrido cambios y acomodamientos a la morfonomémica y la escritura ortográfica del castellano. También, los topónimos evidencian la combinación de elementos léxicos y morfémicos de dos lenguas originarias o de estas con el castellano (topónimos híbridos).

En el caso particular de los topónimos del quechua, éstos registran tres tipos de formación: (1) palabras conformadas por una sola raíz, (2) Palabras derivadas y (3) palabras compuestas. Finalmente, la pesquisa y el análisis de los topónimos nos permite conocer la historia de las lenguas habladas en la zona andina de Áncash, así como la confluencia de grupos socioculturales diferentes en un mismo territorio, muestra de que la diversidad lingüística es una riqueza, un recurso y un valor, que todo ancashino necesita conocer sus orígenes culturales. 


\section{REFERENCIAS BIBLIOGRÁFICAS}

Adelaar, Willem. 1989. «En pos de la lengua culle». En R. Cerrón-Palomino y G. Solís (ed.). Temas de lingüistica amerindia. Lima: UNMSM. 83-105.

Alba, Augusto. 2008. Yungay histórico. Caraz: Ediciones El Inca.

Andrade, Luis y Pérez, Jorge. 2009. Las lenguas del Perú. Lima: Pontificia Universidad Católica del Perú.

Asencios, Feliciano. 2013. «Los topónimos quechumaras y culles en la zona altoandina de Áncash - Perú». Prensa Ancashina, Año XXXIII, No 152. 10-11.

Carranza, Francisco. 2003. Diccionario Quechua Ancashino-Castellano. Madrid: Vervuert e Iberoamericana.

Cerrón-Palomino, Rodolfo. 1988. «Unidad y diferenciación lingüística en el mundo andino». En López (ed.). Pesquisas en lingüistica andina. Lima-Puno: Universidad Nacional del Altiplano, CONCYTEC y GTZ. 121-152.

Cerrón-Palomino, Rodolfo. 2000. Lingüistica aimara. Cuzco: Centro de Estudios Andinos Regionales «Bartolomé de Las Casas».

Cerrón-Palomino, Rodolfo. 2008. Voces del Ande. Ensayos sobre onomástica andina. Lima: Pontificia Universidad Católica del Perú.

Chávez, Amancio. 2003. La toponimia en la zona andina de Áncash con especial referencia sobre el topónimo Shiqui. Lima: UNMSM.

Cuba, María. 2005. «Morfología toponímica de la provincia de Pallasca». Escritura y Pensamiento, Año VIII, No 16. Lima: UNMSM. 113-147.

Heggarty, Paul y Beresford-Jones, David. 2010. «Archeology, language, and the Andean past: principles, methods, and the new 'State of the art'». En Lenguas y sociedades en el antiguo Perú: hacia un enfoque interdisciplinario. Lima: Pontificia Universidad Católica del Perú. 29-60.

Julca, Félix. 2004. «Contacto de lenguas y comunicación intercultural en la zona andina de Ancash». Paqariina, Revista de Investigaciones Lingüisticas y Culturales. $\mathrm{N}^{\circ} 1$. Huaraz: UNASAM. 33-57.

Julca, Félix. 2009a. Quechua Ancashino: una mirada actual. Lima: Fondo Editorial del Pedagógico San Marcos y Care Perú.

Julca, Félix. 2009b. Lengua y Sociedad Andina. Lima: Urpichallay Ediciones.

Julca, Félix. 2014. Wari. El topónimo 'Huari': una aproximación sociobistórica y linguocultural. Huaraz: Hirka Ediciones.

Solís, Gustavo. 1997. La gente pasa, los nombres quedan... Introducción a la toponimia. Lima: Herrera Editores.

Solís, Gustavo. 2003. «Lenguas y contacto en Ancash: bases y prospecto para su estudio». Lengua y Sociedad. № 5. Lima: CILA-UNMSM. 25-38. 
| Félix Julca y Laura Nivin

Torero, Alfredo. 2002. Idiomas de los Andes. Lingüística e historia. Lima: Instituto Francés de Estudios Andinos y Editorial Horizonte.

Fecha de recepción: 24 de enero de 2015

Fecha de aceptación: 16 de marzo de 2015

\section{Correspondencia}

Félix Julca Guerrero

felixjulca@unasaminvestiga.edu.pe 